\title{
Álbuns de figurinhas: uma abordagem via Cadeias de Markov
}

\section{Sticker albums: an approach via Markov chains}

\author{
Leandro Batista Morgado \\ Universidade Federal de Santa Catarina (UFSC), Departamento de Matemática \\ Florianópolis, SC, Brasil \\ leandro.morgado@ufsc.br \\ Leonardo Silveira Borges \\ Universidade Federal de Santa Catarina (UFSC), Departamento de Matemática \\ Florianópolis, SC, Brasil \\ I.s.borges@ufsc.br
}

\section{Informações do Artigo}

(c) (i) \&

Histórico do Artigo

Submissão: 16 de agosto de 2018.

Aceite: 21 de setembro de 2018.

\section{Palavras-chave}

Cadeias de Markov

Distribuição Geométrica

Simulação Computacional

\section{Resumo}

Neste artigo, abordamos o problema do colecionador de um álbum de figurinhas, modelando o problema via cadeias de Markov. Usando resultados de teoria de probabilidade, em especial da distribuição geométrica, estimamos um número de figurinhas a ser compradas para garantir chances razoáveis de completar o álbum, usando como exemplo padrão o álbum oficial da copa do mundo de futebol de 2018. Em seguida, usando simulação computacional, modelamos as sessões de trocas de figurinhas repetidas entre vários colecionadores, verificando que essas trocas reduzem de forma substancial o número de compras necessárias para que o colecionador consiga completar o álbum.

\section{Abstract}

\section{Keywords}

Markov Chains

Geometric Distribution

Computational Simulation
In this paper we address the sticker album collector problem via Markov chains. Using results from probability theory, especially the geometric distribution, we estimate the number of stickers that should be bought to guarantee reasonable chances to complete the album, using as example the official 2018 world cup album. Through numerical experiments we will see how trading repeated stickers with other collectors reduces substantially the amount of stickers that the collector needs to buy to complete the album.

\section{Introdução}

Colecionar figurinhas é um passatempo que transcende gerações. Há muitas décadas, meninos, meninas, jovens e adultos de todas as idades se divertem tentando completar seus álbuns preferidos, seja de Campeonato Brasileiro, Copa do Mundo, animais, super-heróis, entre outros. E os que apreciam essa brincadeira sabem que a sensação de abrir o próximo pacote e obter uma figurinha inédita na coleção é indescritível. Mas, o fato é que, a partir de certo ponto, essa sensação vai ficando cada vez mais rara. Isso porque, à medida que o álbum vai se aproximando do final, as 
figurinhas repetidas se acumulam de uma forma que fica muito mais cômodo recorrer às trocas do que comprar mais pacotes de figurinhas.

Matematicamente, é interessante estimar um número médio de figurinhas que precisamos comprar para ter chances razoáveis de completar o álbum, sem recorrer às trocas. $E$ até que ponto essa estimativa muda se contarmos com uma rede de amigos para trocar figurinhas periodicamente? Essas perguntas podem ser respondidas via teoria de probabilidade fazendo simulações computacionais.

Nas seções seguintes, após modelar o problema via cadeias de Markov, vamos discutir a distribuição geométrica de probabilidade, intimamente ligada ao problema em questão. Em seguida, vamos obter uma cota de figurinhas compradas para garantir boas chances de completar o álbum. Para exemplificar essas estimativas, vamos considerar como exemplo padrão o álbum oficial da copa do mundo de futebol de 2018. Finalmente, para verificar até que ponto vale a pena recorrer às trocas de figurinhas repetidas com outros colecionadores, vamos usar simulação computacional, modelando de que maneira ocorreriam essas trocas em uma situação real. Os resultados dessas simulações, incluindo o número de figurinhas que devem ser compradas em função da quantidade de sessão de trocas realizadas pelo colecionador, são apresentados na última seção.

\section{Modelando o problema}

Para modelar o problema do colecionador de figurinhas, vamos utilizar um processo conhecido como Cadeia de Markov. De uma forma simplificada, uma Cadeia de Markov é um processo estocástico que assume valores em tempo discreto $\left(X_{1}, X_{2}, X_{3}, X_{4}, X_{5}\right.$, e assim sucessivamente), com a propriedade que o estado atual depende apenas do estado imediatamente anterior, sendo irrelevante o conhecimento de todo o passado. Em outras palavras, a probabilidade de $X_{n}$ assumir um determinador valor depende apenas dos valores assumidos por $X_{n-1}$, e não de $X_{n-2}, X_{n-3}$, etc. Essa importante propriedade é conhecida como "perda de memória".

As Cadeias de Markov foram assim denominadas em homenagem ao matemático Andrei Andreyevich Markov (1856-1922), que obteve resultados importantes sobre esse tipo de fenômeno. Usando esses processos, costuma-se modelar fenômenos naturais, como o clima de uma determinada região, ou a migração de indivíduos de uma mesma espécie na Biologia; fenômenos sociais e econômicos, como a transição entre classes sociais de uma determinada comunidade. Para ou- 
tras aplicações interessantes, que podem ser apresentadas em sala-de-aula para alunos do Ensino Médio, recomendamos Ramos [6], bem como Silva, Barone e Basso [8].

Neste artigo, os valores assumidos pelas variáveis aleatórias $X_{1}, X_{2}, X_{3}, \ldots$, que compõem a Cadeia de Markov representam quantas figurinhas distintas o colecionador possui em seu álbum até a compra respectiva. Em outras palavras, $X_{t}=k$ indica que, após a $t$-ésima compra, o colecionador conseguiu colar $k$ figurinhas em seu álbum. Vale considerar também que a propriedade de "perda de memória" que citamos anteriormente de fato ocorre nesse processo, pois basta saber quantas figurinhas distintas o colecionador obteve após a ( $t$-1)-ésima compra para estimar quantas figurinhas o colecionador possuirá após a $t$-ésima. Antes de entrar mais a fundo na discussão específica do problema, apresentamos uma definição formal de Cadeias de Markov:

Definição 2.1. Seja $\Omega$ um conjunto finito. Uma cadeia de Markov em $\Omega$ é uma sequência de variáveis aleatórias $\left\{X_{t}: t \geq 0\right\}$ com valores em $\Omega$, que satisfaz a seguinte propriedade:

$$
\mathbb{P}\left[X_{t+1}=y \mid X_{0}=x_{0}, X_{1}=x_{1}, \ldots, X_{t}=x\right]=\mathbb{P}\left[X_{t+1}=y \mid X_{t}=x\right]
$$

para todo $t \in \mathbb{N}$ e para todos $x, y \in \Omega$. Chamaremos o conjunto $\Omega$ de espaço de estados.

Para mais detalhes sobre esse importante tipo de processo, suas propriedades, classificações e exemplos clássicos, veja Peres [5], Feller [1], entre outros. Agora, considere um álbum com $n$ figurinhas, veja Figura 1. Supomos também inicialmente que o colecionador pretende completar o álbum sem recorrer às trocas de figurinhas repetidas, ou seja, simplesmente vai comprando figurinhas uma a uma, até conseguir o seu objetivo.

Figura 1 - Álbum contendo $n$ figurinhas.

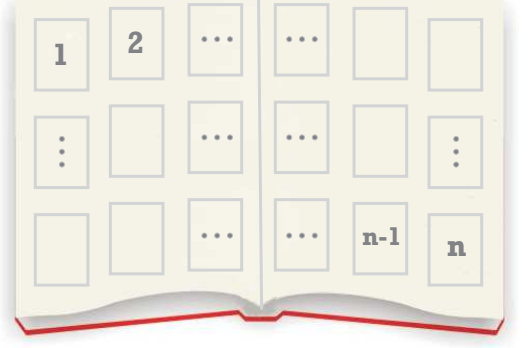

Fonte: Elaboração dos autores.

Vamos assumir também que a coleção é "honesta", ou seja, que todas as figurinhas têm a mesma probabilidade de ser compradas. Como comentamos anteriormente, essa situação pode ser 
modelada por uma sequência de variáveis aleatórias, denotadas por $\left\{X_{t}: t \in \mathbb{N}\right\}$, onde $X_{t}$ representa o número de figurinhas distintas que o colecionador obteve após comprar $t$ figurinhas. Como o total de figurinhas do álbum é $n$, essas variáveis aleatórias podem assumir valores no conjunto $\Omega=\{0,1,2, \ldots, n\}$, denominado espaço de estados. Ademais, as probabilidades de transição entre as variáveis aleatórias estão indicadas no grafo a seguir:

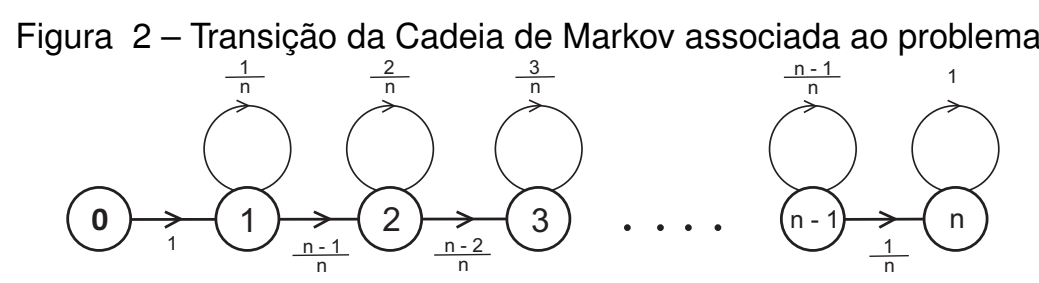

Fonte: Elaboração dos autores.

Uma outra possibilidade para descrever o processo é considerar uma matriz quadrada de ordem $(n+1)$ (número de elementos do espaço de estados), que contém todas as informações sobre a transição do processo. Nesse sentido, denotando por $A$ essa matriz, cada elemento $a_{i j}$ representa a probabilidade de transição do estado $i$ para o estado $j$. No nosso problema, temos que a matriz de transição $A$ é dada por:

$$
\left(\begin{array}{ccccccc}
0 & 1 & 0 & 0 & \ldots & 0 & 0 \\
0 & \frac{1}{n} & \frac{n-1}{n} & 0 & \ldots & 0 & 0 \\
0 & 0 & \frac{2}{n} & \frac{n-2}{n} & \ldots & 0 & 0 \\
& \vdots & & & & & \\
& \vdots & & & & & \\
0 & 0 & 0 & 0 & \ldots & \frac{n-1}{n} & \frac{1}{n} \\
0 & 0 & 0 & 0 & \ldots & 0 & 1
\end{array}\right)
$$

Note que, como não há chances do colecionador perder as figurinhas que já colou em seu álbum, a matriz de transição desse problema é triangular superior.

\section{Estimativas iniciais do número de figurinhas}

Considere também a seguinte variável aleatória que, para cada sequência possível de compras de figurinhas, associa o número mínimo necessário para completar o álbum: $\tau_{f i g}=\min \{t \geq$ 
$\left.0 \mid X_{t}=n\right\}$. Para estimar a quantidade de figurinhas que o colecionador deve comprar para ter uma chance razoável de completar o álbum, destacamos o resultado a seguir:

Proposição 3.1. Na Cadeia de Markov definida acima, tomando $c>0$, temos:

$$
\mathbb{P}\left(\tau_{f i g}>\lceil n \ln (n)+c n\rceil\right) \leq e^{-c},
$$

em que para $a \in \mathbb{R},\lceil a\rceil$ representa o menor inteiro maior que $a$.

Demonstração. Como assumimos que todas as figurinhas têm a mesma probabilidade de ser compradas, a probabilidade de obter a $k$-ésima figurinha do álbum em uma determinada compra é $\frac{1}{n}$. Por uma propriedade básica, a probabilidade de não obter a $k$-ésima figurinha nessa mesma compra é dada por $\left(1-\frac{1}{n}\right)$. Agora, seja $A_{k}$ o evento do colecionador não ter obtido a $k$-ésima figurinha nas $\lceil n \ln (n)+c n\rceil$ primeiras compras. Temos portanto que:

$$
P\left(A_{k}\right)=\left(1-\frac{1}{n}\right)^{\lceil n \ln (n)+c n\rceil} .
$$

Além disso, temos que a probabilidade do álbum não estar completo nas $\lceil n \ln (n)+c n\rceil$ primeiras compras é dado pela união dos eventos $A_{k}$, com $k$ variando de 1 a $n$. Portanto:

$$
\begin{aligned}
\mathbb{P}\left(\tau_{f i g}>\lceil n \ln (n)+c n\rceil\right) & =\mathbb{P}\left(\bigcup_{k=1}^{n} A_{k}\right) \leq \sum_{k=1}^{n} \mathbb{P}\left(A_{k}\right) \\
& =n \cdot\left(1-\frac{1}{n}\right)^{\lceil n \ln (n)+c n\rceil} \\
& =n \cdot\left(1-\frac{1}{n}\right)^{\frac{n \cdot\lceil n \ln (n)+c n\rceil}{n}} \\
& \leq n \cdot \exp \left(\frac{-\lceil n \ln (n)+c n\rceil}{n}\right) \\
& \leq n \cdot \exp \left(\frac{-n \ln (n)-c n}{n}\right) \\
& =\frac{n}{n \cdot e^{c}}=e^{-c},
\end{aligned}
$$

onde a desigualdade $\leq_{(*)}$ decorre do fato que a sequência $\left(\left(1-\frac{1}{n}\right)^{n}\right)_{n \in \mathbb{N}}$ é crescente e converge para $e^{-1}$ quando tomamos $n \rightarrow \infty$ (a esse respeito, veja, por exemplo, Lima [3]).

O resultado anterior significa, em termos gerais, que se tomarmos o número de figurinhas compradas pelo colecionador na forma $\lceil n \ln (n)+c n\rceil$, a probabilidade de não ter completado o álbum de figurinhas decai exponencialmente à medida em que $c$ aumenta. Na seção seguinte, vamos discutir a distribuição geométrica de probabilidade, e como se relaciona com o problema em questão. 


\section{Distribuição Geométrica e trocas de figurinhas}

É fácil constatar que, à medida em que o colecionador fica próximo de completar o álbum, a probabilidade de conseguir uma figurinha inédita fica menor. Por exemplo, a probabilidade de obter a última figurinha para completar a coleção é $\frac{1}{n}$ em cada nova compra. Nesse contexto, podemos nos perguntar:

- Em média, de quantas compras o colecionador precisa para obter esta última figurinha?

- E se faltarem exatamente $m$ figurinhas para completar o álbum, qual o número médio de compras para obter mais uma figurinha inédita?

Podemos usar a teoria da distribuição geométrica de probabilidade para responder esses questionamentos. Intuitivamente, dizemos que uma variável aleatória $Y$ tem distribuição geométrica se $Y$ conta o número de tentativas necessárias para se conseguir o primeiro sucesso, em eventos independentes e identicamente distribuídos.

É importante considerar que optamos pela distribuição geométrica, pois estamos interessados em analisar o desenvolvimento da coleção figurinha a figurinha, ou seja, queremos estimar um número médio de figurinhas necessárias para que o colecionador consiga mais uma inédita. Por outro lado, caso o leitor deseje estimar um número médio para conseguir uma quantidade $k>1$ de figurinhas inéditas, seria necessário trabalhar com soma de variáveis aleatórias com distribuição geométrica com parâmetros diferentes, pois a probabilidade de conseguir o próximo sucesso diminui à medida em que o colecionador aproxima-se do final do álbum. Para mais detalhes sobre essa e outras distribuições de probabilidade, veja por exemplo James [2], Ross [7], entre outros.

Em relação à primeira pergunta acima, esses eventos podem ser descritos como "comprar a próxima figurinha". Se obtermos a única figurinha que falta para o colecionador completar o álbum, temos um sucesso. Caso contrário, temos um fracasso. Nesse sentido, a probabilidade de sucesso em cada evento é $p=\frac{1}{n}$. Assim, podemos calcular a probabilidade de conseguirmos a última figurinha em exatamente $k$ tentativas. Isso ocorre quando obtemos $(k-1)$ fracassos nas primeiras tentativas e sucesso na $k$-ésima tentativa. Como os eventos são independentes, segue que:

$$
\mathbb{P}[Y=k]=(1-p)^{k-1} p
$$


E para obter o número médio de figurinhas que precisamos comprar para obter a última, calculamos a esperança ${ }^{1}$ dessa variável aleatória:

$$
\begin{aligned}
\mathbb{E}[Y] & =\sum_{k=1}^{\infty} k q^{k-1} p=p \sum_{k=1}^{\infty} k q^{k-1} \\
& =p \cdot \frac{d}{d q}\left(\sum_{k=0}^{\infty} q^{n}\right)=p \cdot \frac{d}{d q}\left(\frac{1}{1-q}\right) \\
& =\frac{p}{(1-q)^{2}}=\frac{1}{p} .
\end{aligned}
$$

De fato, o resultado acima vale para qualquer variável aleatória com esta distribuição, onde $p$ é a probabilidade de sucesso de um dos eventos independentes e identicamente distribuídos. Assim, segue que o número médio de figurinhas que devem ser compradas para que o colecionador consiga a última é $\frac{1}{p}=\frac{1}{1 / n}=n$. No mesmo sentido, respondendo à segunda pergunta, caso faltem exatamente $m$ figurinhas para completar o álbum, um sucesso (obter uma figurinha inédita) tem probabilidade $\frac{m}{n}$. E, portanto, o número médio de figurinhas necessárias é $\frac{n}{m}$. Veja que a medida que o colecionador vai completando o álbum, o número médio de compras necessárias para se obter a próxima figurinha inédita aumenta cada vez mais. E o senso comum de que compensa (economicamente) recorrer às trocas de figurinhas repetidas será confirmada nas simulações computacionais apresentadas na última seção. A seguir, vamos discutir especificamente o exemplo do álbum oficial da Copa do Mundo de 2018.

\section{Aplicando as estimativas para o álbum oficial da Copa do Mundo de 2018}

Nesta seção, vamos aplicar os resultados anteriores para obter algumas estimativas concretas sobre o álbum oficial da Copa do Mundo de futebol da Rússia, realizada em 2018. Neste álbum, entre jogadores, escudos de seleções, estádios e outras figurinhas promocionais, o número total de figurinhas é 682. Pela proposição 3.1, sabemos que $\mathbb{P}\left(\tau_{f i g}>\lceil n \ln n+c n\rceil\right) \leq e^{-c}$.

É importante considerar que, se um colecionador quisesse saber o número de figurinhas necessárias para completar o álbum com certeza, a resposta seria "não existe esse número". Obviamente, por se tratar de um processo aleatório, somente podemos estimar o número de figurinhas

\footnotetext{
${ }^{1}$ A esperança de uma variável aleatória $X$ representa o seu valor médio, e se $X$ é discreta, a esperança pode ser calculada por $\mathbb{E}[X]=\sum_{k=1}^{\infty} x_{k} \cdot \mathbb{P}[X=k]$, em que $x_{k}$ representam os valores que essa variável aleatória pode assumir. Para mais detalhes sobre o assunto, veja Meyer [4].
} 
necessário para que ele complete o álbum com uma determinada probabilidade, e é nesse sentido que vamos usar o resultado acima. Para fixar as ideias, estimamos essa probabilidade em $90 \%$. Nesse sentido, queremos estimar uma cota para o número de figurinhas que o colecionador deveria comprar para que a probabilidade deste não completar o álbum seja inferior a 10\%.

Para tanto, tome $c$ tal que $e^{-c}=0,1$. Temos então $c=-\ln 0,1 \approx 2,3$. Fazendo as contas, segue que $\lceil 682 \cdot \ln 682+2,3 \cdot 682\rceil=6018$, e, portanto, $\mathbb{P}\left(\tau_{\text {fig }}>6018\right) \leq 0,1$.

E assim, se o colecionador comprar 6.018 figurinhas, podemos garantir que a chance de completar o álbum da Copa é superior a 90\%. Como o preço de cada figurinha deste álbum é em torno de $R \$ 0,40$ (pois o pacote, contendo 5 figurinhas, foi vendido por $R \$ 2,00$ ), o valor total é de $R \$ 2.407,20$, sem garantias completas de sucesso. Por outro lado, para obter a última figurinha do jeito mais difícil, vimos, na seção referente à distribuição geométrica, que precisamos de uma média de 682 compras, o que corresponde a $R \$ 272,80$. Finalmente, na seção seguinte, vamos usar simulação computacional para verificar como o número de figurinhas compradas diminui expressivamente se o colecionador recorrer às trocas de figurinhas repetidas.

\section{Simulação computacional}

Em nossa simulação computacional, consideramos a seguinte situação: há $2 N$ colecionadores tentando completar um álbum com um total de $n$ figurinhas. Metade dos colecionadores não recorrem às trocas, ou seja, apenas seguem comprando mais figurinhas até completar o álbum. A outra metade forma um grupo que reúne-se periodicamente para as trocas de figurinhas repetidas. Organizamos essas trocas da seguinte maneira:

- Inicialmente, cada jogador desse grupo compra individualmente $f$ figurinhas. Em seguida, os jogadores se reúnem para a sessão de trocas, feita em $t$ rodadas de trocas.

- Em cada rodada de trocas, permutamos os $N$ colecionadores, de forma que eles ocupem, em uma mesa circular, as cadeiras $\{1,2,3, \ldots, N\}$.

- O colecionador da cadeira 1 verifica o álbum do colecionador da cadeira 2, repassando a este suas figurinhas repetidas que possam ser aproveitadas. Em troca, o colecionador da cadeira 2 repassa suas repetidas para o colecionador da cadeira 1 , dando preferência àquelas que o colecionador 1 ainda não possui. Se o colecionador da cadeira 2 não tiver figurinhas para repassar, a troca não acontece. 
- Em seguida, o mesmo processo ocorre com os colecionadores das cadeiras 2 e 3, 3 e 4, e assim sucessivamente, até os colecionadores das cadeiras $\mathrm{N}$ e 1, encerrando uma rodada de trocas. Após $t$ rodadas de trocas, encerramos a sessão, e voltamos ao início do ciclo, com cada colecionador comprando mais $f$ figurinhas.

- Quando algum dos colecionadores desse grupo consegue completar o álbum, este distribui suas figurinhas repetidas de forma aleatória entre os demais, para de comprar figurinhas e não participa da próxima sessão de trocas do grupo.

Conforme mencionamos anteriormente, o álbum da Copa do Mundo de 2018 contém $n=682$ figurinhas, e cada pacote vendido no mercado contém $f=5$ figurinhas. Além disso, consideramos que não há figurinhas repetidas no mesmo pacote. Sendo assim, para completar o álbum o colecionador deve comprar, no mínimo, 137 pacotes. Aqui consideramos que temos $N=100$ colecionadores que não realizam trocas e outros $N=100$ colecionadores que realizam trocas entre si em $t=1, t=3$ e $t=10$ rodadas de trocas seguindo o modelo descrito acima. Definimos que as rodadas de trocas passam a ser realizadas após uma compra inicial de 10 pacotes (50 figurinhas). Os resultados numéricos foram obtidos usando Matlab em um Core i7-4790 com 3,6 GHz e 16GB de memória RAM.

Com a realização de 20.000 simulações distintas apresentamos os resultados a seguir. Para o caso em que não há trocas de figurinhas, o menor número de pacotes comprados foi de 504 (2.520 figurinhas) enquanto que o maior número foi 2.799 (13.995 figurinhas). Ademais, conforme dados na Tabela 1, a maior parte dos colecionadores precisaram comprar entre 701 a 1.100 pacotes e apenas uma pequena parcela foi obrigada a comprar 2.000 ou mais pacotes. Outra constatação interessante, e que confirma a estimativa obtida na seção anterior, é que aproximadamente $90 \%$ dos colecionares precisaram de, no máximo, 1.200 pacotes (total de 6.000 figurinhas) para completar o álbum. A Figura 3 mostra o número de colecionadores que completaram o álbum em função do número de pacotes comprados.

Tabela 1 - Percentual de colecionadores que completaram o álbum em relação ao número de pacotes comprados sem trocas de figurinhas repetidas.

\begin{tabular}{cccccc}
\hline $\mathbf{1 3 7 - 7 0 0}$ & $\mathbf{7 0 1 - 1 . 1 0 0}$ & $\mathbf{1 . 1 0 1 - 1 . 2 0 0}$ & $\mathbf{1 . 2 0 1 - 1 . 6 0 0}$ & $\mathbf{1 . 6 0 1 - 2 . 0 0 0}$ & $\mathbf{2 . 0 0 0 +}$ \\
\hline 1,7995 & 79,4158 & 9,2990 & 8,9653 & 0,4934 & 0,0270 \\
\hline \multicolumn{5}{c}{ Fonte: Elaboração dos autores. }
\end{tabular}


Figura 3 - Colecionadores que completaram o álbum sem rodadas de troca.

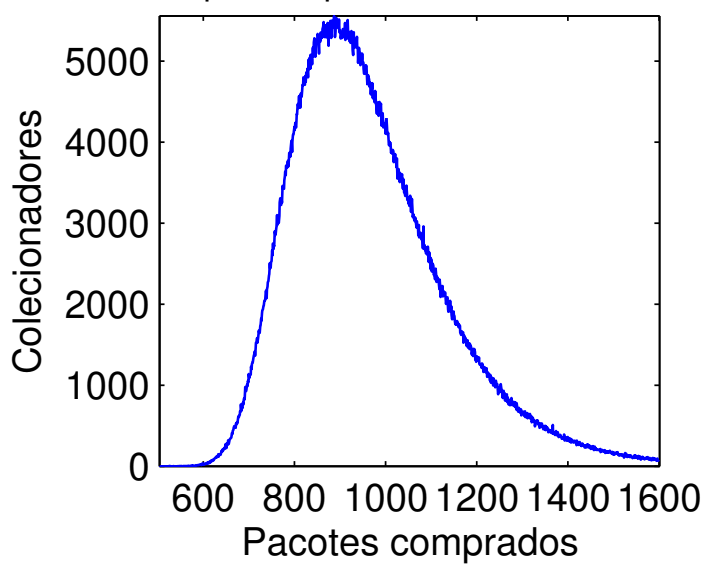

Fonte: Elaboração dos autores.

O cenário em que os colecionadores realizam trocas entre si apresenta, em geral, resultados mais atrativos em relação ao número de pacotes comprados. De fato, as informações disponíveis na Tabela 2 e na Figura 4 revelam que, com 1 rodada de troca, 81,78\% dos colecionadores completaram o álbum comprando entre 181 e 200 pacotes, enquanto que com 3 e 10 rodadas de trocas, $76,89 \%$ e 63,06\% dos colecionadores completaram o álbum comprando entre 161 e 180 pacotes, respectivamente. Com apenas 1 rodada de troca o menor número de compras de pacotes foi de 169 (149 com 3 rodadas e 145 com 10 rodadas) o que caracteriza 845 figurinhas (745 com 3 rodadas e 725 com 10 rodadas). O maior número de pacotes comprados com 1 rodada de troca foi de 1.620 (1.847 com 3 rodadas e 1.721 com 10 rodadas) o que caracteriza 8.100 figurinhas (9.235 com 3 rodadas e 8.605 com 10 rodadas).

Tabela 2 - Percentual de colecionadores que completaram o álbum em relação ao número de pacotes comprados.

\begin{tabular}{ccccccc}
\hline Rodadas de trocas & $\mathbf{1 3 7 - 1 6 0}$ & $\mathbf{1 6 1 - 1 8 0}$ & $\mathbf{1 8 1 - 2 0 0}$ & $\mathbf{2 0 1 - 5 0 0}$ & $\mathbf{5 0 1 - 1 . 0 0 0}$ & $\mathbf{1 . 0 0 0 +}$ \\
\hline 1 & 0 & 16,7190 & 81,7854 & 1,3501 & 0,1419 & 0,0036 \\
3 & 3,0035 & 76,8942 & 9,9169 & 9,6217 & 0,5496 & 0,0141 \\
10 & 12,3885 & 63,0603 & 11,9982 & 11,9406 & 0,5968 & 0,0156 \\
\hline \multicolumn{6}{c}{ Fonte: Elaboração dos autores. }
\end{tabular}


Figura 4 - Colecionadores que completaram o álbum com 1, 3 e 10 rodadas de troca.

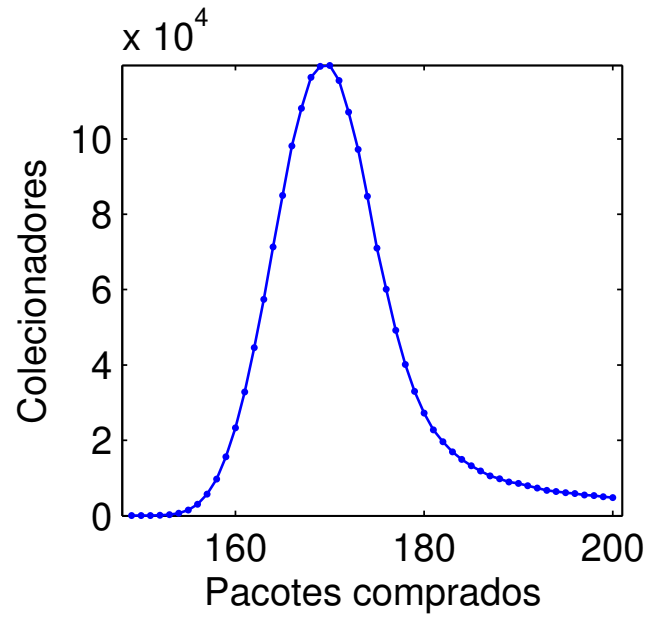

Fonte: Elaboração dos autores.

Outro fato que constatamos nas simulações é que aproximadamente 90\% (com 3 ou 10 rodadas de trocas) e aproximadamente 98\% (com 1 rodada de troca) dos colecionadores completaram o álbum comprando 200 pacotes ou menos. Esse resultado, de certa forma contraintuitivo, devese ao fato que com mais rodadas de trocas, alguns colecionadores conseguem completar o álbum com menos pacotes comprados (veja, por exemplo, a primeira coluna da Tabela 2), reduzindo o número de participantes das sessões seguintes de troca. Finalmente, na tabela a seguir apresentamos a média de pacotes comprados pelo colecionadores para completar o álbum, em cada uma das situações simuladas anteriormente.

Tabela 3 - Média de pacotes comprados em relação ao número de rodadas de trocas.

\section{Sem rodadas de trocas 1 rodada de trocas 3 rodadas de trocas 10 rodadas de trocas}

\begin{tabular}{llll}
\hline 966,2717 & 185,4115 & 183,0337 & 183,0063 \\
\hline
\end{tabular}

Fonte: Elaboração dos autores.

Nesse contexto, fica evidente que o colecionador que recorre às trocas de figurinhas repetidas obtém resultados significativamente melhores do que aqueles que não o fazem, mesmo que seja realizada apenas uma rodada de trocas em cada encontro periódico com outros colecionadores (resultados com $t=1$ ). 


\section{Considerações finais}

Vimos inicialmente que o problema do colecionador de figurinhas pode ser modelado via cadeias de Markov. Para tanto, definimos o espaço de estados como as possíveis quantidades de figurinhas inéditas que o colecionador possui em um determinado momento. $E$, de fato, a probabilidade de, a cada compra, o colecionador passar ao próximo estado (isto é, obter mais uma figurinha inédita) não depende de todo o histórico do processo, mas apenas de sua situação no instante anterior. Trata-se da propriedade de perda da memória, típica dos processos markovianos.

Em seguida, supondo a situação em que o colecionador não recorre às trocas de figurinhas repetidas, obtemos uma estimativa do número de figurinhas que ele precisaria comprar para garantir chances razoáveis de completar o álbum. Trata-se do resultado descrito na proposição 3.1. Aplicando essa estimativa ao caso particular do álbum oficial da Copa do Mundo de futebol de 2018 (que contém 682 figurinhas), vimos que, com pouco mais de 6.000 figurinhas, o colecionador tem probabilidade superior a $90 \%$ de completar o álbum. Posteriormente, realizando simulação computacional nessa mesma situação (sem as trocas de figurinhas repetidas), obtemos valores muito próximos a essa cota.

Outro aspecto de teoria de probabilidade relacionado ao tema do colecionador de figurinhas é a distribuição geométrica, que abordamos em seguida. Estimamos o número médio de figurinhas (isto é, a esperança da variável aleatória correspondente) que devem ser compradas pelo colecionador para conseguir a próxima inédita. Concluímos também que esse número médio aumenta significativamente à medida que o colecionador aproxima-se do final do álbum, o que justifica a ideia de que obterá resultados bem melhores se recorrer às trocas de figurinhas repetidas.

Na última seção, via simulação computacional, verificamos até que ponto essas trocas influenciam no número de pacotes que devem ser comprados pelo colecionador para completar o álbum. Para uma comparação efetiva, simulamos inicialmente a situação sem as trocas; em seguida, a situação de um número considerável de colecionadores que após as compras, reúnem-se periodicamente para efetuar as trocas de figurinhas repetidas. Neste último caso, fizemos a simulação variando o número de sessões de troca (quantidades de pessoas com que o colecionador interage durante cada encontro realizado).

$\mathrm{E}$, de fato, as simulações realizadas confirmam o senso comum de que, em geral, os colecionadores que recorrem às trocas conseguem resultados muito melhores do que aqueles que tentam completar apenas comprando figurinhas. Por outro lado, aumentar o número de rodadas de trocas 
em cada sessão não traz tantos benefícios aos colecionadores. Por exemplo, para conseguir completar o álbum, o número médio de pacotes comprados pelos colecionadores que não recorreram às trocas foi 966,27; em um grupo de 100 colecionadores com 1 rodada de trocas, esse número médio de pacotes diminuiu para 185,41, e no mesmo grupo com 3 rodadas de trocas, essa média foi reduzida para 183,03 pacotes comprados.

\section{Referências}

FELLER, W. An Introduction to Probability Theory and its Applications. v. 1. New York, 1993.

JAMES, B. Probabilidade: um curso em nível intermediário. Rio de Janeiro: Instituto de Matemática Pura e Apicada, 2010.

LIMA, E. Curso de Análise. v. 1. Rio de Janeiro: Instituto Nacional de Matemática Pura e Aplicada, 2012.

MEYER, P. Probabilidade: aplicações a estatística. São Paulo: LTC, 1983.

PERES, Y. Markov Chains and Mixing Times. American Mathematical Society, 2008.

RAMOS, Y. T. A. C. Aplicações de cadeias de Markov no ensino médio. 2017. 53 f.

Dissertação (Mestrado profissional em Matemática) - Programa de Pós-Graduação do Instituto de Matemática, Estatística e Computação Científica, Campinas, 2017.

ROSS, S. A First Course in Probability. 8. ed. Bookman, 2010.

SILVA, R. S., BARONE, D. A. C. e BASSO, M. V. A. Cadeias de Markov e Geogebra: modelagem matemática e possibilidades para a construção de conceitos através do uso de objetos virtuais. In: V Jornada Nacional de Educação Matemática e XVIII Jornada Regional de Educação Matemática, 2014, Passo Fundo. Anais da V Jornada Nacional de Educação Matemática e XVIII Jornada Regional de Educação Matemática. Passo Fundo: Editora da Universidade de Passo Fundo, 2014. v. 1. p. 1-12. 